\title{
Transapical transcatheter aortic valve implantation: Follow-up to 3 years
}

\author{
Jian Ye, MD, ${ }^{\mathrm{a}}$ Anson Cheung, MD, ${ }^{\mathrm{a}}$ Samuel V. Lichtenstein, MD, PhD, ${ }^{\mathrm{a}}$ Fabian Nietlispach, MD, \\ Saad Albugami, MD, ${ }^{\mathrm{b}}$ Jean-Bernard Masson, MD, ${ }^{\mathrm{b}}$ Christopher R. Thompson, MD, ${ }^{\mathrm{b}}$ Brad Munt, MD, ${ }^{\mathrm{b}}$ \\ Robert Moss, MD, ${ }^{\mathrm{b}}$ Ronald G. Carere, MD, ${ }^{\mathrm{b}}$ W. R. Eric Jamieson, MD, ${ }^{\mathrm{a}}$ and John G. Webb, MD ${ }^{\mathrm{b}}$
}

Background: We performed the first human case of successful transapical transcatheter aortic valve implantation on a beating heart in October 2005, and therefore we have the longest follow-up on transapical aortic valve implantation in humans. We now report clinical and echocardiographic outcomes of transapical aortic valve implantation in 71 patients.

Methods: Between October 2005 and February 2009, 71 patients (44 female) underwent transcatheter transapical aortic valve implantation with either 23- or 26-mm Edwards Lifesciences transcatheter bioprostheses. All patients with symptomatic aortic stenosis were declined for conventional aortic valve replacement owing to unacceptable operative risks and were not candidates for transfemoral aortic valve implantation because of poor arterial access. Clinical and echocardiographic follow-ups were performed before discharge, at 1 and 6 months, and then yearly. The mean follow-up was $12.9 \pm 11.5$ months with a total of 917.3 months of follow-up.

Results: Mean age was $80.0 \pm 8.1$ years and predicted operative mortality was $34.5 \% \pm 20.4 \%$ by logistic EuroSCORE and $12.1 \% \pm 7.7 \%$ by The Society of Thoracic Surgeons Risk Calculator. Valves were successfully implanted in all patients. Twelve patients died within 30 days (30-day mortality: $16.9 \%$ in all patients, 33\% in the first 15 patients, and $12.5 \%$ in the remainder), and 10 patients died subsequently. Overall survival at 24 and 36 months was $66.3 \% \pm 6.4 \%$ and $58.0 \% \pm 9.5 \%$, respectively. Among 59 patients who survived at least 30 days, 24 - and 36-month survivals were $79.8 \% \pm 6.4 \%$ and $69.8 \% \pm 10.9 \%$, respectively. Late valve-related complications were rare. New York Heart Association functional class improved significantly from preoperative $3.3 \pm 0.8$ to $1.8 \pm 0.8$ at 24 months. The aortic valve area and mean gradient remained stable at 24 months $\left(1.6 \pm 0.3 \mathrm{~cm}^{2}\right.$ and $10.3 \pm 5.9 \mathrm{~mm} \mathrm{Hg}$, respectively).

Conclusion: Our outcome suggests that transapical transcatheter aortic valve implantation provides sustained clinical and hemodynamic benefits for up to 36 months in selected high-risk patients with symptomatic severe aortic stenosis. (J Thorac Cardiovasc Surg 2010;139:1107-13)

\section{Supplemental material is available online.}

Aortic valve replacement (AVR) with cardiopulmonary bypass (CPB) has been the only treatment that offers both symptomatic relief and the potential for improved longterm survival and hence is the treatment of choice for

\footnotetext{
From the Division of Cardiac Surgery ${ }^{\mathrm{a}}$ and the Division of Cardiology, ${ }^{\mathrm{b}}$ St Paul's Hospital, University of British Columbia, Vancouver, British Columbia, Canada.

Disclosures: Drs Ye, Webb, Munt, and Cheung are consultants to Edwards Lifesciences Inc, Irvine, California. Dr Webb has also received financial support for research from Edwards Lifesciences Inc. Dr Moss has received honoraria from Edwards. The remaining authors have no financial relationship to disclose.

Read at the Thirty-fifth Annual Meeting of The Western Thoracic Surgical Association, Banff, Alberta, Canada, June 24-27, 2009

Received for publication June 24, 2009; revisions received Oct 22, 2009; accepted for publication Oct 31, 2009.

Address for reprints: Jian Ye, MD, Division of Cardiac Surgery, St Paul's Hospital, B493, 1081 Burrard St, Vancouver, BC, Canada, V6Z 1Y6 (E-mail: jye@ providencehealth.bc.ca).

$0022-5223 / \$ 36.00$

Copyright (c) 2010 by The American Association for Thoracic Surgery

doi:10.1016/j.jtcvs.2009.10.056
}

patients with symptomatic severe degenerative aortic stenosis. ${ }^{1}$ However, inasmuch as a considerable number of elderly patients with symptomatic severe aortic stenosis have significant comorbidities, open heart AVR with CPB can be associated with an unacceptable perioperative mortality and morbidity in this group. Over the past 5 years, the development of minimally invasive transcatheter valve implantation has been explored. ${ }^{2-13}$ Transarterial and transapical transcatheter aortic valve implantation (AVI) has been explored by cardiologists and cardiac surgeons worldwide. Many reports have shown favorable early clinical and echocardiographic outcomes with transarterial or transapical AVI. We reported the first successful transcatheter transapical AVI through a left minithoracotomy and the apex of the left ventricle without CPB in humans, ${ }^{11,12}$ followed by our early clinical experience with transapical transcatheter AVI without CPB. ${ }^{14-16}$ Our early experience and that of others ${ }^{17}$ have shown that transapical transcatheter AVI definitely relieves aortic stenosis and significantly improves valve-related symptoms. We now report clinical and echocardiographic outcomes of transapical AVI in our first 71 patients. 


\section{Abbreviations and Acronyms \\ AVI = aortic valve implantation \\ AVR = aortic valve replacement \\ $\mathrm{CPB}=$ cardiopulmonary bypass \\ NYHA $=$ New York Heart Association \\ STS $=$ The Society of Thoracic Surgeons}

\section{METHODS}

The transapical procedure was approved by the Therapeutic Products Directorate, Department of Health and Welfare, Ottawa, Canada, for compassionate clinical use in patients with symptomatic severe aortic stenosis deemed not to be candidates for routine open heart AVR and unsuitable for percutaneous transfemoral AVI.

\section{Patient Selection}

All patients were assessed independently by at least two cardiologists and two cardiac surgeons. They were accepted for the procedure on the basis of the consensus that conventional surgery was an excessively high risk in terms of anticipated mortality and morbidity. Patient or physician preference alone was not considered adequate. Therefore, this cohort of patients was usually elderly and frail with multiple comorbidities. Porcelain aorta was the most common single reason for declining conventional AVR. Currently, there is no single risk calculator that can accurately estimate operative risk in the elderly. EuroSCORE and The Society of Thoracic Surgeons (STS) score were not used to determine the fitness for open heart AVR. Written informed consent was obtained.

Transapical AVI was recommended if aortofemoral angiography and/or computed tomographic angiography revealed aortic and/or iliofemoral arterial anatomy unfavorable for the transfemoral approach, such as the dimension of iliofemoral arteries of less than $7.0 \mathrm{~mm}$ for the $23-\mathrm{mm}$ valve and less than $8 \mathrm{~mm}$ for the 26-mm valve if the RetroFlex 3 delivery system (Edwards Lifesciences, Irvine, Calif) was used or less than $6.5 \mathrm{~mm}$ if the NovaFlex delivery system (Edwards) was considered. The characteristics of 71 patients are listed in Table E1.

\section{Prosthetic Valve Implantation}

The procedure of transapical transcatheter AVI was described in detail in our previous publications. ${ }^{11,14,15}$ All patients including our first patient underwent transapical AVI on the beating heart through an approximately 5 -cm anterolateral minithoracotomy in an operating room.

Heparin was administered to achieve an activated clotting time of 300 seconds or more. With the use of fluoroscopic, aortographic, and transesophageal echocardiographic imaging, balloon valvuloplasty and then deployment of the bioprosthesis were performed during rapid ventricular pacing to minimize ventricular ejection. Cribier-Edwards transcatheter equine pericardial tissue valves (Edwards) were used in the first 8 patients and SAPIEN THV bovine pericardial tissue valves (Edwards) in subsequent patients. Either 23-mm or 26-mm transcatheter tissue valves were used. Patients were maintained on aspirin indefinitely and on clopidogrel for 3 months. Warfarin was routinely used in 8 patients in our early series, of whom 2 patients had gastrointestinal bleeding within 30 days. Therefore, we stopped routine use of warfarin unless there were other indications, such as atrial fibrillation or an existing mechanical valve.

\section{Follow-up and Data Collection}

All patients were carefully followed up by cardiac surgeons, cardiologists, clinical fellows, and clinical research coordinators. Clinical followup and echocardiography were obtained before discharge (69 patients) and at 1 (51 patients), 6 (42 patients), 12 (35 patients), 24 (17 patients), and 36 (4 patients) months. The mean follow-up was $12.9 \pm 11.5$ months, with a total of 917.3 months. The longest follow-up was 37.3 months. Every patient (including our first patient) who underwent transapical isolated AVI is included in the report. Data are presented as mean \pm standard deviation. One-way analysis of variance with generalized linear model was used to compare echocardiographic parameters (aortic valve area, mean transaortic pressure gradient, aortic insufficiency, left ventricular ejection fraction, and mitral regurgitation) and New York Heart Association (NYHA) class between different time points. Multiple comparisons among the different time points were performed using the least significant difference post hoc test. Bonferroni correction was used to evaluate the significance of the multiple comparisons. The Kaplan-Meier method was used to generate survival curves. The statistical analyses were performed with the SAS (version 9.1.3) statistical software package (SAS Institute, Inc, Cary, NC).

\section{RESULTS \\ Patients}

Mean age of 71 patients ( 44 female) was $80.0 \pm 8.1$ years. Predicted operative mortality was $34.5 \% \pm 20.4 \%$ by logistic EuroSCORE and $12.1 \% \pm 7.7 \%$ by the STS Risk Calculator. Seventeen patients were not accepted for conventional AVR despite low estimates of operative mortality (STS score $<10 \%$ ) because of porcelain ascending aorta, severe lung disease, or end-stage liver cirrhosis.

\section{Intraoperative Outcome}

Transapical transcatheter AVI via a left anterior minithoracotomy without CPB was successfully performed in all 71 patients. Bioprostheses were $23 \mathrm{~mm}$ in diameter in 28 patients and $26 \mathrm{~mm}$ in 43 patients. In 2 patients a second transcatheter bioprosthesis was implanted for significant paravalvular leaks owing to suboptimal positioning of the first transcatheter bioprosthesis. One patient died immediately after completion of the procedure in the operating room, probably as a result of obstruction of the left coronary ostium by a native bulky calcified aortic valve. This patient also had significant intraoperative bleeding owing to difficult hemostasis at the puncture site of the left ventricular apex. A second patient had cardiac arrest at the time when minithoracotomy was performed and died of heart failure despite subsequent successful AVI with the support of femorofemoral CPB. Another patient had a perforation of a severely calcified aortic root after deployment of the transcatheter valve, for which emergency open heart aortic root replacement was done.

\section{Early Clinical Outcome}

Of the 71 patients, 12 patients died within 30 days after AVI. Of the 12 deaths, 2 occurred intraoperatively. The overall 30 -day mortality was $16.9 \%$. In the initial 15 patients there were 5 deaths for an early mortality of $33 \%$. After this initial learning curve, 7 of the remaining 56 patients died for an early mortality of $12.5 \%$. Predicted operative mortality by STS Risk Calculator and EuroSCORE were similar for the first 15 cases and the subsequent 56 cases (Table 1). The causes of postoperative 
TABLE 1. Predicted and observed 30-day mortality

\begin{tabular}{lccc}
\hline & & & Remaining \\
& All 71 cases & First 15 cases & $\mathbf{5 6}$ cases \\
\hline Predicted mortality (\%) & & & \\
Logistic EuroSCORE & $34.5 \pm 20.4$ & $31.0 \pm 20.0$ & $36.0 \pm 20.8$ \\
STS Score & $12.1 \pm 7.7$ & $10.0 \pm 6.0$ & $12.7 \pm 8.1$ \\
Observed mortality (\%) & 16.9 & 33.3 & 12.5 \\
Age (y) & $80.0 \pm 9.0$ & $78.0 \pm 11.0$ & $80.0 \pm 7.2$ \\
\hline
\end{tabular}

STS, The Society of Thoracic Surgeons.

10 deaths included pneumonia (2 patients), ischemic bowel (2 patients), vascular complication/ischemic leg (2 patients), pulmonary embolism (1 patient), multiple organ failure ( 2 patients), and massive hemorrhage from chest tube reinsertion in a patient with existing liver failure and coagulopathy (1 patient). Six $(8.5 \%)$ patients required new pacemaker implantation within 30 days after the procedure, of whom 2 patients had sick sinus syndrome, and 4 (5.6\%) patients had heart block. One patient's course was complicated by cerebrovascular accident $(1.4 \%)$.

\section{Late Clinical Outcomes}

Of 59 patients surviving more than 30 days, 10 patients died of non-valve-related complications. The causes of the deaths include cancer (1 patient), lung diseases (severe chronic obstructive pulmonary disease and/or pneumonia/ sepsis in 4 patients), myocardial infarction (1 patient), multiple organ failure (congestive heart failure, severe chronic renal failure, and chronic obstructive pulmonary disease in 2 patients), gastrointestinal bleeding (1 patient), and multiple factors/organ failure (cachexia and anorexia in 1 patient).

Late valve-related complications were very uncommon. There was no valve thrombosis, endocarditis, or structural valve deterioration. Overall survival at 24 and 36 months was $66.3 \% \pm 6.4 \%$ and $58.0 \% \pm 9.5 \%$, respectively. Among patients (59 patients) who survived at least 30 days, 24- and 36-month survivals were 79.8\% $\pm 6.4 \%$ and $69.8 \% \pm 10.9 \%$, respectively. If the first 15 patients were excluded as an initial learning curve, 24-month survival in 56 patients was $68.1 \% \pm 7.9 \%$. Figures 1 to 3 illustrate the Kaplan-Meier survival after transapical transcatheter AVI.

The majority of the patients $(86.2 \%)$ had NYHA class III and IV heart failure symptoms before the procedure. Remarkable improvement in functional class was observed after transapical AVI, and $83.9 \%$ and $75 \%$ patients had NYHA class I or II heart failure symptoms at 12 and 24 months' follow-up, respectively. Mean NYHA class decreased from $3.3 \pm 0.8$ preoperatively to $1.7 \pm 0.8$ and $1.8 \pm 0.8$ at 12 and 24 months, respectively (Figure E1, $B$ ).

\section{Echocardiographic Follow-up}

Early echocardiography after the procedure documented an increase in aortic valve area from $0.6 \pm 0.2 \mathrm{~cm}^{2}$ preoper-

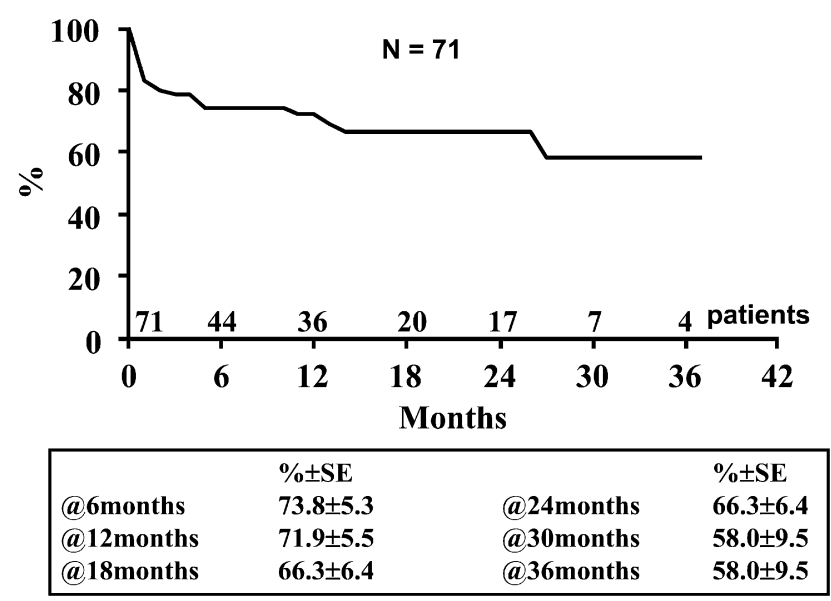

FIGURE 1. Kaplan-Meier survival in 71 patients. $S E$, Standard error.

atively to $1.4 \pm 0.3 \mathrm{~cm}^{2}$ at 1 month and a reduction in mean transaortic pressure gradient from $43.6 \pm 16.3 \mathrm{~mm} \mathrm{Hg}$ preoperatively to $10.1 \pm 3.9 \mathrm{~mm} \mathrm{Hg}$ at 1 month. The prosthetic valve area and transvalvular pressure gradient remained stable up to 36 months' follow-up (Figure 4, A and $B$ ). Left ventricular ejection fraction increased slightly after AVI from a mean of $55.5 \% \pm 12.6 \%$ preoperatively to $61.2 \% \pm 7.0 \%$ at 24 months (Figure E1, A).

Echocardiography demonstrated that $77.6 \%$ of the patients had paravalvular leak, of whom $46.6 \%$ had trivial leak, $25.9 \%$ mild leak, and 5.2\% moderate leak after the procedure. Aortic regurgitation was assessed by a combination of color Doppler, pressure half-time, vena contracta width, and flow reversal techniques. The assessment scheme we have used is similar to that used by Kapur and associates. $^{18}$ The degree of aortic regurgitation remained unchanged and clinically insignificant during follow-up (Figure E2, A). There was no significant change in mitral regurgitation during follow-up (Figure E2, $B$ ).

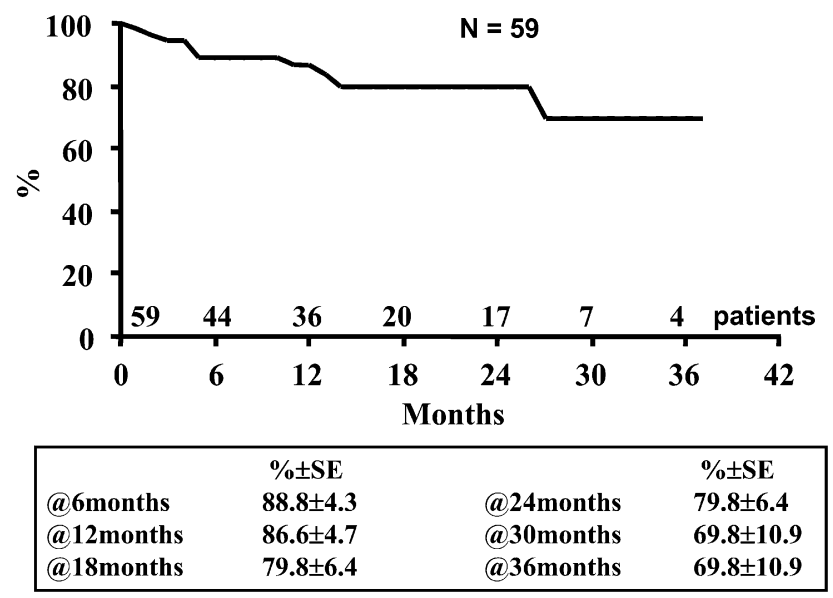

FIGURE 2. Kaplan-Meier survival in 59 patients who survived at least 30 days. $S E$, Standard error. 


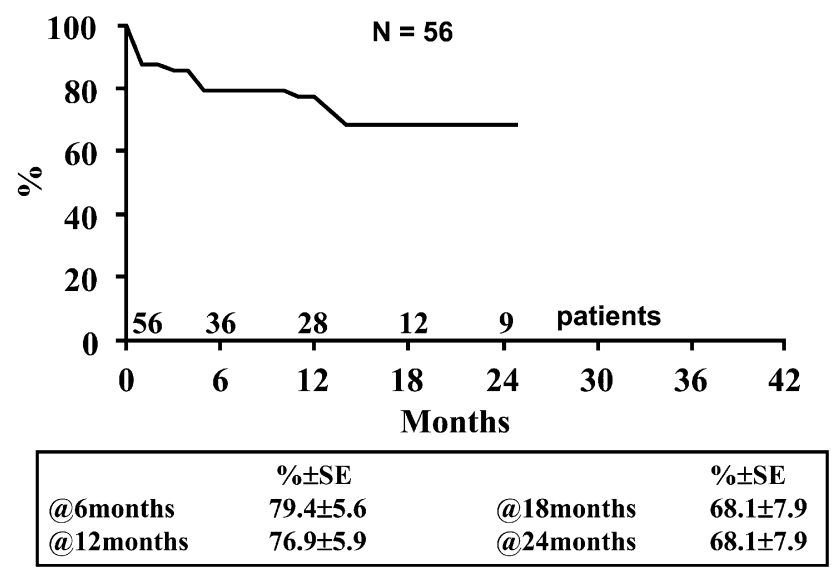

FIGURE 3. Kaplan-Meier survival in 56 patients excluding the first 15 cases. SE, Standard error.

\section{DISCUSSION}

This report represents the longest follow-up data on transapical transcatheter AVI in a relatively large number of patients $(\mathrm{n}=71)$ being monitored clinically and echocardiographically up to 37 months. We did not exclude our initial patients despite the significant initial learning curve.

Reported early mortality for septuagenarians and octogenarians undergoing primary isolated AVR ranges from $6.6 \%$ to $16.7 \%$, whereas reported operative morbidity including atrial fibrillation in elderly patients ( $>70$ years old) after AVR with or without coronary artery bypass was up to $64 \%$ to $76 \%{ }^{19-21}$ We reviewed 86 patients 80 years of age or older who underwent isolated AVR between 1998 and 2002 in our University of British Columbia valve database, and the early operative mortality was $5.8 \%$ in the co-

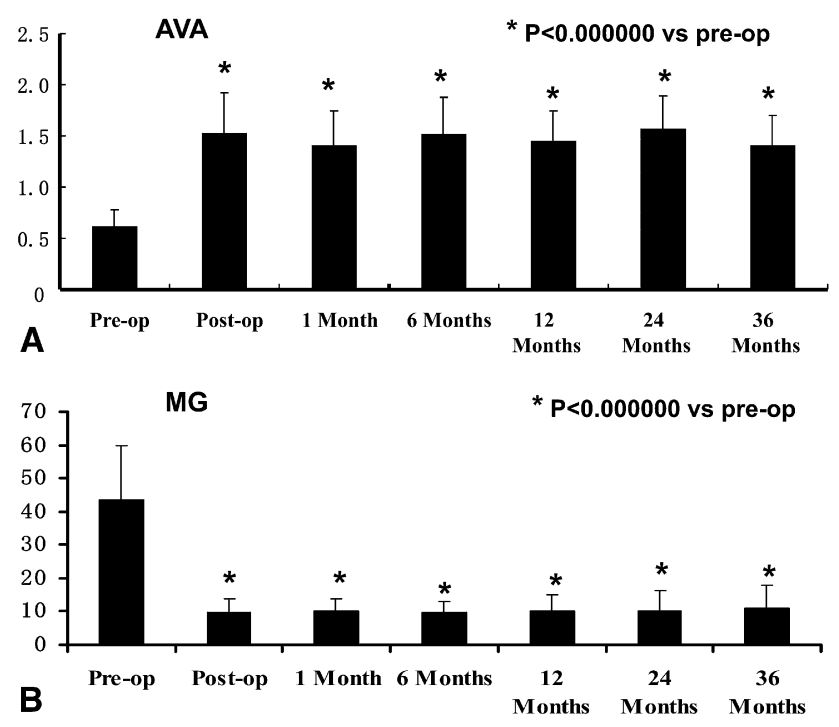

FIGURE 4. Echocardiographic follow-up. A, Aortic valve area $\left(\mathrm{cm}^{2}\right)$. B, Transaortic valve pressure gradient $(\mathrm{mm} \mathrm{Hg}) . A V A$, Aortic valve area; $M G$, mean gradient. hort of patients accepted for conventional AVR (unpublished data). However, the real risk of conventional AVR remains unclear in high-risk patients, who often do not undergo AVR. The predicted operative mortality in the cohort of our patients was $34.5 \% \pm 20.4 \%$ by logistic EuroSCORE and $12.1 \% \pm 7.7 \%$ by STS Risk Calculator. Our observed 30-day mortality was $33.3 \%$ in the first 15 patients and significantly decreased to $12.5 \%$ after the initial learning curve. Improved teamwork with cumulative experience, improved apical hemostasis, use of hybrid operating room, understanding risk factors for potential fatal complications, and aggressive postoperative care probably contributed to the decease in early mortality. The observed mortality after passing the initial learning curve is similar to the STS predicted operative mortality. However, it should not be concluded that transapical transcatheter AVI might not reduce operative mortality relative to conventional AVR, inasmuch as the STS prediction model may underestimate operative mortality in elderly patients or patients with some specific comorbidities. The STS prediction model does not reflect many significant risk factors that were frequently observed in our patients. These risk factors include end-stage liver disease, prolonged preoperative hospital stay, general deconditioning, frailty, immobility owing to other medical conditions, significant abnormalities of other valves, severity of peripheral vascular and aortic disease, end-stage lung disease, porcelain aorta, previous chest wall radiation, and prior infected sternotomy. These conditions contribute to the early and late mortality and morbidity after transapical transcatheter AVI, and more so for conventional open heart AVR.

It is widely documented that average survival of patients with symptomatic aortic stenosis with symptoms of congestive heart failure is approximately 2 to 3 years. Patients with aortic stenosis who were accepted for but refused to have conventional AVR have very poor survival. In a report by Schwarz and associates, ${ }^{1} 144$ patients with isolated aortic stenosis were offered surgery; 125 patients had AVR and 19 patients refused AVR due to personal choice. Survival at 3 years in the 125 surgically treated patients was $87 \%$, in contrast to $21 \%$ in 19 patients who did not undergo an operation. In a report by Kojodjojo and associates, ${ }^{22} 3$ groups of patients 80 years of age or greater were followed up for 3 years to investigate the impact of the patient's choice to refuse conventional AVR on survival. Survival of patients who were accepted for AVR but refused surgery was approximately $40 \%$ at 3 years, significantly lower than that of the group of patients who were accepted and underwent AVR (approximately $87 \%$ at 3 years). The 62 patients who were declined by surgeons for conventional AVR had the lowest survival at 1,2, and 3 years (approximately $50 \%, 25 \%$, and $10 \%$, respectively). Patients who were declined for surgery in Kojodjojo's study had a lower predicted operative risk as compared with our patients who underwent 
transcatheter AVI (logistic EuroSCORE $20.2 \% \pm 13.4 \%$ vs $34.5 \% \pm 20.4 \%$ in our patients). Reported 1-year survivals after transcatheter AVI ranged between $65 \%$ and $80 \%$. In our study 1-, 2-, and 3-year survivals were $71.9 \% \pm$ $5.5 \%, 66.3 \% \pm 6.4 \%$, and $58.0 \% \pm 9.5 \%$, respectively. The 1-, 2-, and 3-year survivals in the cohort of patients who survived the first 30 days were better $(86.6 \% \pm$ $4.7 \%, \quad 79.8 \% \pm 6.4 \%$, and $68.8 \% \pm 10.9 \%$, respectively). Survival in our selected high-risk elderly patients who underwent transapical AVI was much better than that of the cohort of elderly patients who were declined conventional AVR in Kojodjojo's report, consistent with improved survival in comparison with conservative management. The current ongoing randomized PARTNER clinical trial may provide more definitive information on whether transapical AVI may improve survival in selected highrisk patients with aortic stenosis.

Our data has shown that the initial learning curve does significantly influence early mortality $(33.3 \%$ in the first 15 patients vs $12.5 \%$ in the remainder of the patients), but does not significantly affect 2-year survival $(68.1 \% \pm$ $7.9 \%$ in patients excluding the first 15 patients vs $66.3 \%$ $\pm 6.4 \%$ in all patients). The study has also demonstrated that late valve-related complications are rare and that there is no structural valve deterioration or nonstructural valve dysfunction during follow-up. However, long-term durability of the transcatheter tissue valve remains to be determined.

Transapical AVI can provide significant symptomatic benefit. The majority of survivors had NYHA class I-II heart failure symptoms at follow-up. Patients with significant lung disease generally have less improvement in dyspnea. Most of the survivors were satisfied with their cardiac condition and were living independently at follow-up.

Echocardiographic follow-up demonstrated stable function of the balloon-expandable transcatheter bioprosthetic valves. Trivial to mild paravalvular regurgitation was common immediately after deployment of the bioprostheses but was clinically insignificant and remained stable up to 37 months. A frequent location of trivial to mild paravalvular leaks is at the posterior portion of the annulus, where there is relatively less tissue consisting of a thin layer of the fibrotic aortomitral curtain. More significant paravalvular leaks are infrequent and most likely result from incomplete deployment or suboptimal positioning of bioprostheses. Optimal positioning, correct measurement of the aortic annular size, and selection of an appropriate size of a transcatheter valve are the important factors to reduce the incidence of paravalvular leaks. The mean valve area of the transcatheter valve was approximately 1.4 to 1.5 $\mathrm{cm}^{2}$ and mean transaortic valve pressure gradient was approximately $10 \mathrm{~mm} \mathrm{Hg}$, remaining stable up to 37 months.

Concomitant severe mitral regurgitation in the presence of severe aortic stenosis is generally considered an indication for a combined aortic and mitral valve procedure with an attendant increase in operative mortality and morbidity, particularly in patients with advanced age and significant comorbid conditions. In the present series, $36.9 \%$ of patients had grades 3 and 4 mitral regurgitation preoperatively, and they appeared to tolerate the transapical AVI procedure intraoperatively. The mitral regurgitation remained unchanged or slightly decreased after transapical AVI. This suggests that a conservative approach to coexisting mitral valve regurgitation may be a reasonable approach in selected high-risk patients. Left ventricular systolic function (ejection fraction) remained stable or improved slightly after transapical AVI.

Immediate device embolization after valve deployment is a documented complication ${ }^{23}$ but was not observed in this cohort undergoing transapical AVI. Theoretically, better coaxial positioning and stabilization of the device during deployment can be achieved with the transapical approach because of a short, straight line from the apex to the annulus, relative to the transfemoral approach. This complication decreases significantly with the clinical experience of surgeons, interventional cardiologists, and echocardiographers.

In summary, the initial learning curve with transapical AVI affects early operative mortality but does not appear to influence late survival. Our clinical and echocardiographic outcomes suggest the survival benefits of transapical transcatheter AVI in selected high-risk patients with symptomatic aortic stenosis and the structural and functional stability of the transcatheter bioprostheses in elderly patients. The transapical transcatheter AVI is an alternative to conventional AVR in selected high-risk patients with symptomatic severe aortic stenosis. The next challenge is to better identify those with a very poor expected midterm survival despite successful transcatheter AVI. This could be termed "'a second learning curve." The in vivo long-term durability of the transcatheter bioprosthesis remains to be determined. At present, conventional AVR remains the first-line therapy for symptomatic severe aortic stenosis.

\section{References}

1. Schwarz F, Baumann P, Manthey J, Hoffmann M, Schuler G, Mehmel HC, et al The effect of aortic valve replacement on survival. Circulation. 1982;66: 1105-10.

2. Andersen HR, Knudsen LL, Hasenkam JM. Transluminal implantation of artificial heart valves. description of a new expandable aortic valve and initial results with implantation by catheter technique in closed chest pigs. Eur Heart J. 1992; 13:704-8.

3. Cribier A, Eltchaninoff H, Bash A, Borenstein N, Tron C, Bauer F, et al. Transcatheter implantation of balloon-expandable prosthetic heart valves. Early results in an animal model. Circulation. 2001;104(Suppl 2): I552.

4. Boudjemline Y, Bonhoeffer P. Steps toward percutaneous aortic valve replacement. Circulation. 2002;105:775-8.

5. Webb JG, Munt B, Makkar R, Naqvi T, Dang N. A percutaneous stent-mounted valve for treatment of aortic or pulmonary valve disease. Catheter Cardiovasc Interv. 2004;63:89-93.

6. Grube E, Laborde JC, Zickmann B, Gerckens U, Felderhoff T, Sauren B, et al First report on a human percutaneous transluminal implantation of a selfexpanding valve prosthesis for interventional treatment of aortic valve stenosis. Catheter Cardiovasc Interv. 2005;66:465-9. 
7. Cribier A, Eltchaninoff H, Bash A, Borenstein N, Tron C, Bauer F, et al. Percutaneous transcatheter implantation of an aortic valve prosthesis for calcific aortic stenosis. Circulation. 2002;106:3006-8.

8. Cribier A, Eltchaninoff H, Tron C, Bauer F, Agatiello C, Sebagh L, et al. Early experience with percutaneous transcatheter implantation of heart valve prosthesis for the treatment of end-stage inoperable patients with calcific aortic stenosis. J Am Coll Cardiol. 2004;43:698-703.

9. Cribier A, Eltchaninoff H, Tron C, Bauer F, Agatiello C, Nercolini D, et al. Treatment of calcific aortic stenosis with the percutaneous heart valve. Mid-term follow-up from the initial feasibility studies: the French experience. $J$ Am Coll Cardiol. 2006;47:1214-23.

10. Webb JG, Chandavimol M, Thompson C, Ricci DR, Carere R, Munt B, et al. Percutaneous aortic valve implantation retrograde from the femoral artery. Circulation. 2006; 113:842-50.

11. Ye J, Cheung A, Lichtenstein SV, Carere RG, Thompson CR, Pasupati S, et al. Transapical aortic valve implantation in man. J Thorac Cardiovasc Surg. 2006; 131:1194-6.

12. Lichtenstein SV. Closed heart surgery. Back to the future. J Thorac Cardiovasc Surg. 2006;131:941-3.

13. Chandavimol M, McClure SJ, Carere R, Thompson CR, Ricci DR, MacKay M, et al. Percutaneous aortic valve implantation: a case report. Can J Cardiol. 2006;22:1159-61.

14. Lichtenstein SV, Cheung A, Ye J, Thompson CR, Carere RG, Pasupati S, et al. Transapical transcatheter aortic valve implantation in humans. Initial clinical experience. Circulation. 2006;114:591-6.

15. Ye J, Cheung A, Lichtenstein SV, Pasupati S, Carere RG, Thompson CR, et al. Six-month outcome of transapical transcatheter aortic valve implantation in the initial seven patients. Eur J Cardiothorac Surg. 2007;31:16-21.

16. Ye J, Cheung A, Lichtenstein SV, Altwegg LA, Wong DR, Carere RG, et al. Transapical transcatheter aortic valve implantation: 1-year outcome in 26 patients. J Thorac Cardiovasc Surg. 2009;137:167-73.

17. Walther T, Simon P, Dewey T, Wimmer-Greinecker G, Falk V, Kasimir MT, et al. Transapical minimally invasive aortic valve implantation: multicenter experience. Circulation. 2007;116(suppl I):I240-5.

18. Kapur KK, Fan P, Nanda NC, Yoganathan AP, Goyal RG. Doppler color flow mapping in the evaluation of prosthetic mitral and aortic valve function. $J \mathrm{Am}$ Coll Cardiol. 1989;13:1561-71.

19. Task Force on the Management of Valvular Heart Disease of the European Society of Cardiology. Guidelines on the management of valvular heart disease. Eur Heart J. 2007;428:e1-39.

20. Kawachi Y, Arinaga K, Nakashima A, Toshima Y, Kawano H, Kosuga T. Aortic valve replacement in patients age 70 years and older: early and late results. Artif Organs. 2002;26:706-10.

21. Glock Y, Faik M, Laghzaoui A, Moali I, Roux D, Fournial G. Cardiac surgery in the ninth decade of life. Cardiovasc Surg. 1996;4:241-5.

22. Kojodjojo P, Gohil N, Barker D, Youssefi P, Salukhe TV, Choong A, et al. Outcomes of elderly patients aged 80 and over with symptomatic, severe aortic stenosis: impact of patient's choice of refusing aortic valve replacement on survival. QJM. 2008;101:567-73.

23. Webb JG, Pasupati S, Humphries K, Thompson C, Altwegg L, Moss R, et al. Percutaneous transarterial aortic valve replacement in selected high-risk patients with aortic stenosis. Circulation. 2007;116:755-63.

\section{Discussion}

Dr Michael J. Mack (Dallas, Tex). My conflict of interest disclosure is that I am a member of the Partner trial and therefore I am a consultant to Edwards Lifesciences (Irvine, Calif).

I would like to congratulate the team in Vancouver for their pioneering efforts, not only Dr Ye but also Drs Anson Cheung and John Webb. I would like to highlight some of their experience and ask 4 questions.

Jian, your series comprises 71 patients at a mean follow-up of 12.9 months. The 30 -day mortality is $16.9 \%$ with an STS predicted mortality of $12.5 \%$. Two-year survival is $66 \%$ and 3-year survival is $58 \%$. I think this needs to be put in a context that everybody needs to understand: this is an integrated program with the transfemoral approach, and this is a "transfemoral first" program so that the patients in whom the transapical approach was used in a way are the "worst of the worst." Not only are they patients who are in inoperable condition or at very high risk for surgery, but they are not candidates for the transfemoral approach either. Thus, in a way you have had to develop this procedure on the patients in the worst condition.

First question: In the first 15 patients, you have highlighted that there is a $33 \%$ mortality and that that was due to the learning curve. What have you learned so that the rest of us can avoid that learning curve? Is it patient selection? Is it specific aspects of the technique? Is it early-stage technology? What are the specific learning curves that the rest of us can avoid?

Dr Ye. Thank you very much for your comments. I would like to make several points to emphasize in avoiding complications and the learning curve.

1. Patient selection: I think some really ill and elderly patients with end-stage organ diseases should not be recommended for this procedure because correcting aortic stenosis would not necessarily reverse their poor outcome.

2. Hybrid operating room with a high-quality imaging system: We performed our initial cases in our regular operating room with a portable $\mathrm{C}$-arm fluoroscope that provides suboptimal images during the procedure. A hybrid operating room with a high-quality imaging system improves optimal positioning of transcatheter valves and success rate of the procedure.

3. Surgical technique: Surgical technique is particularly important in avoiding fatal complications, such as massive apical bleeding.

4. Performers' experience and knowledge and team work: Performers should understand potential major complications and appropriate ways to deal with these complications on an emergency basis.

5. Postoperative care: These are really sick patients and the postoperative care is extremely important, especially in preventing and managing pneumonia, line infection, sepsis, or acute renal failure. In this cohort of patients, infection, particularly pneumonia, frequently contributes to poor outcomes. Prevention of deep vein thrombosis and pulmonary embolism is particularly important in these elderly patients because they are frequently immobile.

Dr Mack. Second question: This is a transfemoral first program. What percent of the transcatheter valves are performed by a transfemoral approach and what percent by a transapical one? As the transfemoral delivery systems get smaller, more steerable, with more low-profile nose cones, what do you see as the ultimate role of the transapical approach?

Dr Ye. Great questions. At our centers, approximately two thirds and one third of accepted patients for transcatheter AVI underwent the transfemoral and transapical approaches, respectively. At this point, there is no evidence to suggest one approach is better than another approach. Continuing improvement in the transfemoral delivery systems might change the role of the transapical approach. However, I believe both approaches will be advanced simultaneously as each approach has its own advantages and disadvantages. At present, the transapical approach is usually performed by thoracic surgeons and the transfemoral mainly by cardiologists. Inasmuch as I am a cardiac surgeon, it may be biased for me to answer your question. I believe that the transapical approach will continue to play an important 
role in transcatheter valve therapy because it has unique advantages compared with the transfemoral approach: (1) a shorter and straight route to approach heart valves, which provides better stabilization, coaxial alignment, and positioning relative to the transfemoral approach; (2) a better way for aortic valve implantation in patients with previous mitral valve replacement because stabilization is more important in these patients given high risks of displacement of the balloon during valve deployment (inflating balloon against a strut of mitral prosthesis); (3) an optimal approach for aortic valve-in-valve implantation into failed bioprostheses; and (4) an optimal approach to access the mitral valve. We have performed more than 10 cases of transapical valve-invalve implantation into failed bioprostheses at the mitral, aortic, and the tricuspid positions. At present, the transapical approach is the only way for valve-in-valve implantation. Therefore, I believe the transapical will continue to play a major role in this evolving transcatheter technology. There is no randomized trial to compare the transfemoral and transapical approaches at this time, and the patient populations in the transapical and transfemoral groups are quite different, as Dr Mack mentioned. At this point, no one is able to claim that transfemoral is better than transapical because the populations in these 2 groups are very different. I think a randomized controlled clinical trial to compare surgery, transfemoral, and transapical approaches is necessary.

Dr Mack. If you had to start a transcatheter valve program all over again knowing what you know right now, would it be a transapical first or transfemoral first? Second, if you had an elderly relative, 90 years old, STS risk of 10, would you recommend conventional surgery, transapical, or transfemoral?

Dr Ye. Those are excellent questions. I think the transapical approach is pretty safe. More important, it provides a better positioning and stabilization during valve implantation. To start a program, I think there is no reason that we cannot start the transapical first. With development of apical closure devices, the transapical could become a better approach.

Regarding the second part of your question on the therapeutic option for a 90-year-old patient with aortic stenosis, I think it is difficult to give a definite answer at this moment because no randomized trial has been performed to compare surgical, transfemoral, and transapical. Personally, I would not make a recommendation just based on the age and STS score, without my assessment of the patient. Generally speaking, for a patient 90 years old or greater, I would recommend either the transapical or transfemoral approach unless the patient is in very good condition with limited comorbidities. 

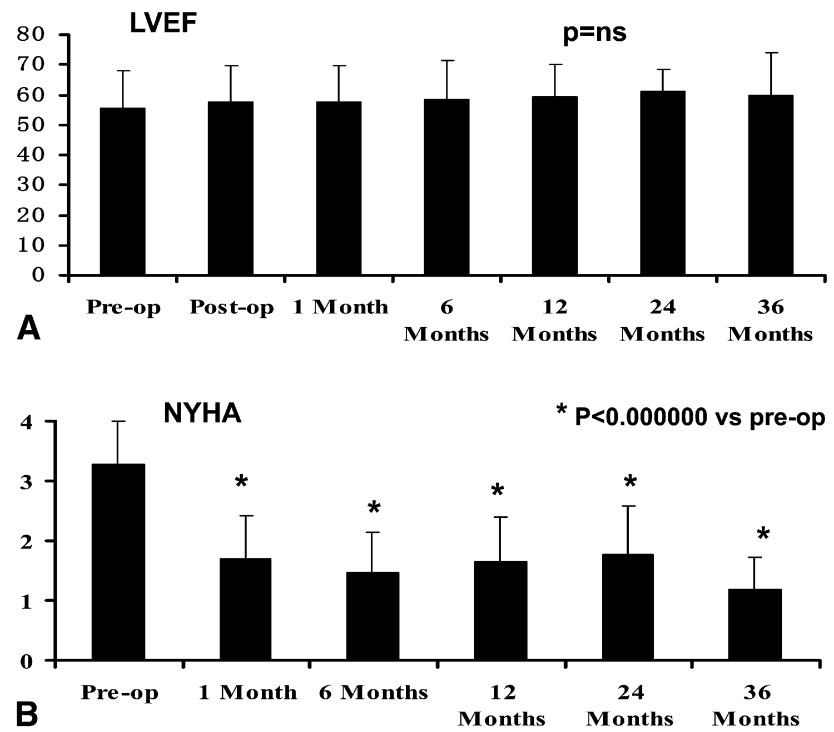

FIGURE E1. Echocardiographic and clinical follow-up. Left ventricular ejection fraction (LVEF \%) (A), and New York Heart Association (NYHA) functional class (1-4) (B). $n s$, Not significant.
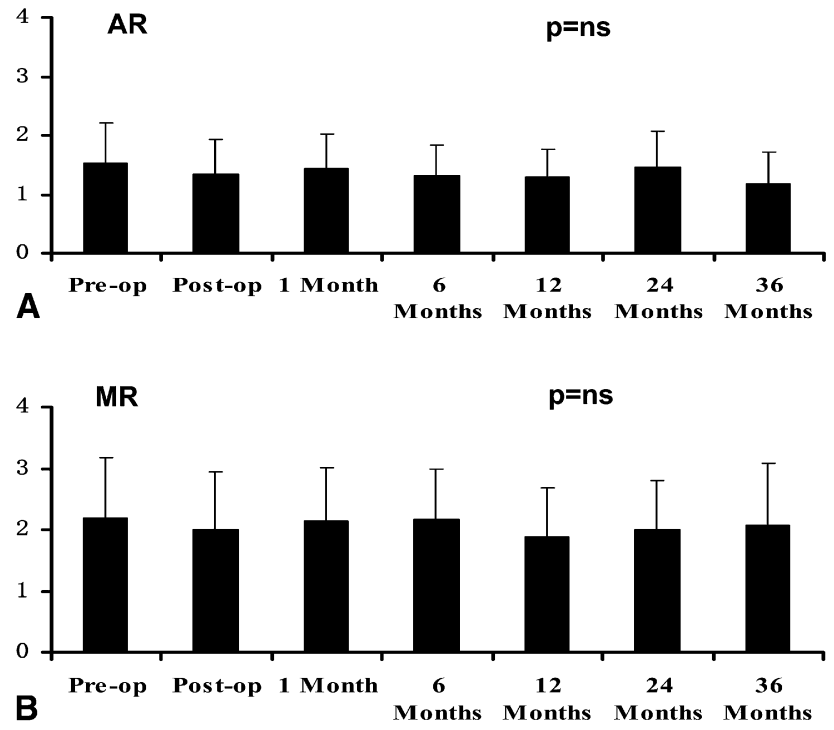

FIGURE E2. Echocardiographic follow-up: aortic regurgitation $(A R)$ $(1=$ trivial, $2=$ mild, $3=$ moderate, $4=$ severe $)(\mathrm{A})$ and mitral regurgitation $(M R)(1=$ trivial, $2=$ mild, $3=$ moderate, $4=$ severe $)(B)$.
Table E1. Baseline characteristics of 71 patients

\begin{tabular}{lcc}
\hline \multicolumn{1}{c}{ Characteristics } & No. of patients & Percentage \\
\hline Age $(80.0 \pm 8.1$ y)* & & \\
$\geq 90$ y & 6 & 8.5 \\
$80-89$ y & 36 & 50.7 \\
Female sex & 44 & 62.0 \\
Hypertension & 64 & 90.1 \\
Diabetes & 20 & 28.2 \\
Coronary artery disease & 53 & 74.6 \\
Prior myocardial infarction & 50 & 70.4 \\
Severe lung disease & 20 & 28.2 \\
Prior coronary artery bypass grafting & 31 & 43.7 \\
History of cerebral ischemic event & 22 & 31.0 \\
Peripheral vascular disease & 61 & 85.9 \\
History of gastrointestinal bleeding & 12 & 16.9 \\
Estimated glomerular filtration & 41 & 57.7 \\
$\quad$ rate $<60$ mL/min & & \\
Ejection fraction $<50 \%$ & 18 & 26.5 \\
Pulmonary hypertension & & \\
$\quad$ Systolic pressure $\geq 60 \mathrm{~mm} \mathrm{Hg}$ & 15 & 21.1 \\
Systolic pressure $50-59 \mathrm{~mm} \mathrm{Hg}$ & 6 & 8.6 \\
$\quad$ Systolic pressure $40-49 \mathrm{~mm} \mathrm{Hg}$ & 21 & 30.0 \\
Porcelain aorta & 15 & 21.1 \\
History of smoking & 49 & 69 \\
Atrial fibrillation & 24 & 33.8 \\
Permanent pacemaker & 13 & 18.3 \\
Preoperative hemoglobin $<120 \mathrm{mg} / \mathrm{L}$ & 33 & 46.5 \\
\hline
\end{tabular}

*Mean \pm standard deviation 